\title{
O PRINCÍPIO DA SOLIDARIEDADE AMBIENTAL E O PROBLEMA DA JUSTIÇA ENTRE GERAÇÕES
}

\section{Jackelline Fraga Pessanha ${ }^{1}$ Marcelo Sant'Anna Vieira Gomes ${ }^{2}$}

RESUMO: A Constituição Federal é denominada por muitos como Constituição verde, que parte da ideia de que os direitos que ali estão inseridos devem ser lidos de maneira ampliativa. Porém, o que se percebe é que o Legislativo vem buscando ultrapassar os limites impostos, em nome do progresso da humanidade. Assim sendo, ao se realizar uma análise da Justiça ambiental sob o pensamento de John Rawls, será possível compreender como os parâmetros atinentes à posição original e ao véu da ignorância podem ser úteis à preservação de um meio ambiente para a geração atual e para as futuras.

Palavras-chaves: Meio ambiente; Justiça; Rawls; Véu da ignorância; Direito entre gerações; Cooperação entre os povos.

\section{THE PRINCIPLE OF ENVIRONMENTAL SOLIDARITY AND THE PROBLEM OF JUSTICE BETWEEN GENERATIONS}

ABSTRACT: The Brazillian Constitution is named green Constitution too, which starts an idea that rights are inserted there must be read in an expansive way. However, what is perceived is that the Legislative has been seeking to exceed the limits imposed, in the name of humanity progress. Therefore, when carrying out an analysis of environmental justice by John Rawls's thought, it will be possible to understand how the parameters pertaining to the original position and the veil of ignorance can be useful for the preservation of an environment for the actual generation and for the future ones.

Keywords: Environment; Justice; Rawls; Veil of ignorance; Right between generations; Cooperation between peoples.

\section{INTRODUÇÃO}

"A Amazônia é nosso bem comum. Estamos todos envolvidos, e a França está provavelmente mais do que outros que estarão nessa mesa [do G7], porque nós somos

\footnotetext{
${ }^{1}$ Direito Ambiental - UEMG/Ituiutaba. Doutoranda em Direito - UniCEUB. Mestre em Direito - FDV. Líder do Grupo de Pesquisa Estado \& Direito: Estudos Contemporâneos, da UEMG/Ituiutaba. Advogada. e-mail: jackellinepessanha@yahoo.com.br.

${ }^{2}$ Docente de Teoria do Processo e Direito Processual Civil - UEMG/Ituiutaba. Mestre pela UFES. Líder do Grupo de Pesquisa Estado \& Direito: Estudos Contemporâneos, da UEMG/Ituiutaba. e-mail: mrsantanna@yahoo.com.br.
} 
amazonenses. A Guiana Francesa está na Amazônia”’3. A frase anteriormente divulgada foi divulgada em cadeia nacional, pelo presidente francês Emmanuel Macron, no contexto das queimadas que se desencadearam na Floresta Amazônica entre meados de 2019 e o ano de 2020.

Por mais que ela gere estranheza em alguma medida, na prática, o representante de Estado nada mais fez que deixar clara a posição da França em relação ao meio ambiente. Essa é uma das facetas da solidariedade ambiental. É importante observar que essa solidariedade deve ser observada sob dois vieses: o primeiro, sob o ponto de vista da solidariedade entre nações, assim como o segundo, sob a perspectiva da solidariedade intergeracional (solidariedade entre as gerações).

A Constituição da República de 1988 (BRASIL, 1988), desde o seu art. 3º, estabelece dentre os objetivos da nação, o de construir uma sociedade livre, justa e solidária (art. $3^{\circ}$, inciso I), jungido à cooperação entre os povos para o progresso da humanidade (art. $4^{\mathrm{o}}$, inciso IX). Fazendo esse corte epistemológico, a partir daqui quando se afirmar em solidariedade, o ponto será a solidariedade intergeracional, ao passo que quando se falar da solidariedade entre os povos, será utilizada a expressão: cooperação entre povos. Mesmo assim, ambas fazer parte do conceito macro de solidariedade ambiental.

Todo esse contexto pode ser inserido, também, do art. 225, da Carta Magna, ao trazer que "todos têm direito ao meio ambiente ecologicamente equilibrado, bem de uso comum do povo e essencial à sadia qualidade de vida, impondo-se ao Poder Público e à coletividade o dever de defende-lo e preservá-lo para as presentes e futuras gerações” (BRASIL, 1988). Essa proteção para as presentes e futuras gerações, demonstra a importância que o legislador constitucional conferiu ao tema. Tamanha é a relevância, que a doutrina alça o meio ambiente a um status protetivo que deu voz ao preceito hermenêutico do in dubio pro natura (BELCHIOR, 2011, p. 265).

Dessa maneira, vários autores, ao longo de séculos, trabalharam concepções do que vem a ser justiça e o que faz com que ela seja considerada a vertente mais adequada a ser estabelecida para a solidariedade ambiental. Assim, como corte metodológico, com o ideal hipotético-dedutivo, estuda-se como a teoria de John Rawls pode ter inspirado a Constituição

\footnotetext{
3 SEM AUTOR: Para Macron, Amazônia é 'bem comum' e pede 'mobilização de potências' contra desmatamento. Jornal G1. Sem cidade, 24. Ago. 2019. Seção Mundo. Disponível em: <https://g1.globo.com/mundo/noticia/2019/08/24/para-macron-amazonia-e-bem-comum-e-pedemobilizacao-de-potencias-contra-desmatamento.ghtml>. Acesso em: 22. Jan. 2021.
} 
de 1988 na concepção de solidariedade, principalmente no que concerne a matéria ambiental.

Para tanto, é utilizando-se da teoria da justiça, que se pauta pela análise dos princípios da liberdade e da igualdade, bem como à posição original, ao véu da ignorância, estágio de aplicação a casos particulares e princípio da poupança, que se pretende defender que a solidariedade ambiental pode ser alcançada tanto sob a perspectiva intergeracional, como de cooperação entre os povos.

$\mathrm{O}$ artigo é dividido em três tópicos. O primeiro, descreve as premissas utilizadas por John Rawls para fundamentar sua teoria da Justiça. Já o segundo tópico, é debatida a questão do princípio da solidariedade ambiental, para que, ao final seja possível definir os fundamentos pelos quais o princípio da solidariedade ambiental tem fincado seus pilares na teoria rawlsiana, através da análise do problema da justiça entre gerações conjugada à solidariedade ambiental.

\section{A TEORIA DA JUSTIÇA DE RAWLS}

Justiça é uma palavra que se adéqua a diversos significados. Cada pensador, ao longo de séculos, estabeleceu parâmetros aos quais se adequavam melhor aos preceitos nos quais entendiam como adequados. Analisando o dicionário da Língua Portuguesa, tem-se que a respectiva palavra tem o sentido de que "é a particularidade do que é justo e correto, é a virtude que consiste em dar ou deixar a cada um o que por direito lhe pertence" (HOUAISS e VILLAR, 2009, p. 261).

A concepção de justiça, por diversas vezes, é comparada com o ideal de direito, quando protege a sociedade dos poderes arbitrários, exercendo a normalização de condutas, apresentando oportunidades iguais às pessoas e amparando os desfavorecidos. Nesse sentido, a justiça era concebida por símbolos gregos e romanos (FERRAZ JÚNIOR, 2003, p. 25). Para os gregos o direito era justo quando garantia a igualdade entre as pessoas e os pratos estavam nivelados. E para os romanos, a justiça era distribuída por meio da balança, quando o fiel ficava completamente vertical.

Esse ideal de justiça dos Gregos e Romanos, pautados em símbolos e significados, passou por várias novas significações, principalmente no que concerne a expressão jus, que começou usada mais em sentido moral e por exame de atuação jurisdicional. Assim, o presente texto não pretende detalhar os ideais de justiça grego ou romano e nem a concepção 
de justiça, conforme os requisitos e particularidades estabelecidas por diversos autores. Nesse sentido, aqui optou-se por dissecar o tema à luz do pensamento de John Rawls.

É importante deixar claro que o autor possui um ideal de justiça como equidade, na medida em que estabelece uma estrutura de sociedade, na qual são distribuídos direitos e deveres fundamentais, dividindo as vantagens decorrentes da cooperação entre os indivíduos (RAWLS, 2001, p. 18). Para gerar justiça, é necessário seguir dois princípios, o primeiro deles é de que "cada pessoa deve ter um direito igual ao mais abrangente sistema total de liberdades básicas iguais que seja compatível com um sistema semelhante de liberdade para todos" (RAWLS, 2002, p. 266).

Desde já, destaca-se que justiça não é gerar igualdade entre as pessoas, como se fossem iguais. O pensador traz uma visão contratualista diversa daquela já estabelecida há séculos. Daí deriva a ideia de que as desigualdades econômicas e sociais devem ser levadas em consideração, de forma a trazer “(a) o maior benefício possível para os menos favorecidos, obedecendo às restrições do princípio da poupança justa, e (b) sejam vinculadas a cargos e posições abertos a todos em condições de igualdade equitativa de oportunidades" (TREDANARO, 2017, p. 68).

Dessa forma, Rawls fundamenta sua teoria no paradigma de que a justiça deve ser concebida pelo viés imparcial, ao afirmar que "concepção de fairness ou fair play que clama por uma justiça estabelecida através de um jogo limpo, imparcial (justice fairness)" (FURLAN, 2012, p. 9). Daí a ideia de se desprover de todas as suas preconcepções ou percepções de mundo, para estabelecer os princípios basilares da sociedade, uma vez que Rawls pretende elaborar conceitos de justiça alternativo a concepção utilitarista.

Assim, para a concepção de justiça como equidade deve levar em consideração as questões sociais, econômicas, políticas, liberdades, igualdade, democracia, ou seja, só há justiça em uma sociedade liberal e democrática que realiza o devido respeito à igualdade de direitos. Isso porque, ao afirmar que a igualdade é elemento indispensável a concretização do ideal de justiça, confirma e possibilita a concretização de liberdade (MÖLLER, 2006, p. 26).

Basicamente, o que se teria com isso, seria o que o autor chega a denominar de consenso sobreposto, no qual seria possível "conferir um fundamento razoável para a cooperação entre os adeptos das inúmeras doutrinas abrangentes, já que se situariam em uma posição de 'imparcialidade' em relação a elas” (SOUZA NETO, SARMENTO, 2016. p. 208). Isso quer afirmar que a sociedade é plural e diversa, motivo pelo qual, dificilmente seria 
possível se chegar um consenso, em razão das múltiplas ideias que almejam.

Por esse motivo, a teoria de Rawls pretende com que, ao menos, as pessoas consigam analisar os fatos, de uma maneira imparcial, a ponto de ver em que medida os pensamentos podem ser convergentes. Em suma, haveria uma necessidade em se ter tolerância entre os pensamentos diversos. Para estabelecer uma melhor descrição do fenômeno de justiça, o autor entendia que havia a necessidade de se pensar mais no que se trata sob preceitos coletivos, que propriamente em direitos puramente individuais (FARO, 2012, p. 2016).

Por isso, as adequações de justiça tratada por Rawls (RAWLS, 2002, p. 66) visam o bem comum. Isso quer dizer que, para que a justiça seja alcançada de forma equânime e distributiva, é necessário o que o indivíduo esteja abrangido pelo que se denomina de véu da ignorância. Isso porque, o véu da ignorância traria uma maior cooperação entre os indivíduos, para o bem de todos. O indivíduo não deve conhecer sua classe social, gênero, nacionalidade e outros atributos comuns a todos.

A partir daí, estaria ele vestido do véu da ignorância, a partir da concepção de que sua posição original seria desconhecida. A posição original é o primeiro de quatro estágios. A posição original busca um desenvolvimento social, que "antecedem o retorno dos cidadãos deliberantes a seus lugares na sociedade real, para o reconhecimento dos princípios de justiça" (MÖLLER, 2006, p. 96).

Quando a posição original é desconhecida, ao tomar decisões o indivíduo consegue atingir, de maneira mais eficaz, o parâmetro mais adequado ao que se tem como ideário de justiça (FARO, 2012, p. 2018), pois é desprovido de todos as suas preconcepções que será possível se atingir o ideário de justiça mais igualitário. Isso faz com que o debate em coletividade gere uma melhor distribuição dos bens à coletividade. Trata-se, portanto, se solucionar um contexto em que todos estão vinculados à posição original.

Ao se estar de acordo com o véu da ignorância, tem-se presente que não há, portanto, a ameaça da posição original (POGGE, 2007, p. 64), motivo pelo qual, não há como se pensar de forma diversa, a ponto de entender de que lado estaria mais vantajoso. Em outras palavras, não é possível que a pessoa se distancie da situação a ponto de identificar o que, de fato, faria mais sentido à sua realidade.

Do consenso, é possível estabelecer direitos, mas direitos nos quais aquele grupamento está mais inserido. A questão não é somente que estejam ali inseridos naquele contexto, por não pensarem no geral e, por consequência, não trazerem uma distribuição de 
justiça social de maneira mais adequada.

Assim, a posição original é o ponto de partida da discussão. Mas, Rawls deixa evidenciado que para que o ideal de justiça seja concretizado, é necessário que sejam cumpridos mais outros 3 (três) estágios. Assim, os demais estágios são: a convenção constituinte, a promulgação da lei e a aplicação a casos particulares (RAWLS, 2002, p. 213).

Assim sendo, em outras palavras, o autor defende que a formação da convenção constituinte como estágio de teoria da justiça tem como pressuposto o de "escolher uma Constituição que garanta uma igual liberdade de consciência, regulamentada somente de acordo com argumentos geralmente aceites e limitada apenas quando tais argumentos demonstrem um conflito razoavelmente certo com as bases da própria ordem pública" (SILVA, 1998, p. 195). Perceba-se que essa designação nada mais faz do que demonstrar que, após a saída da posição original, os indivíduos estariam aptos a buscar essa Constituição mais adequada, entre aquelas opções que, tentassem atingir o máximo de distribuição de vantagens aos indivíduos.

Como terceiro estágio de justiça para a teoria rawlsiana está, como afirmado anteriormente, o de promulgação das leis (estágio legislativo). Esse estágio, basicamente, tem como foco a criação legislativa, com base nos ditames e influências da Constituição, na medida em que "obriga que as políticas econômicas e sociais se orientem para a maximização das expectativas no longo prazo dos menos afortunados, respeitando as condições de igualdade equitativa de oportunidades e mantendo as liberdades iguais para todos" (NUNES JÚNIOR, 2005, p. 218).

Adaptando e adequando o preceito acima, tem-se presente que é de conhecimento público e notório que qualquer legislação criada, por certo, buscará seu fundamento de validade na Constituição, tendo em vista que essa é o ápice do ordenamento jurídico, quando comparado à ilustração de uma pirâmide que compõe o ordenamento jurídico (KELSEN, 2011, p. 219).

Por fim, John Rawls entende que o último estágio seria o estágio de aplicação ao caso concreto. Esse estágio também é denominado de estágio judicial, na medida em que "todos têm a possibilidade de acesso pleno aos fatos, de vez que os limites ao conhecimento são relaxados; todas as restrições, suspensas” (NEDEL, 2000, p. 74). É aqui que a justiça, de fato, se concretiza.

Enquanto nos estágios anteriores, a justiça ainda estava no mundo das ideias e das 
perspectivas, quando se chega ao último estágio é que ela se concretiza na prática. Seria, portanto, o véu da ignorância aquele capaz de auxiliar nesse contexto para se chegar a uma justiça ambiental mais eficaz. A partir desse ponto se percebe que a melhor contribuição de Rawls para o Direito Ambiental é, justamente, a de tornar as pessoas um pouco mais interligadas aos objetivos comuns e desprovidas dos desejos individualistas.

O que se deve ter em mente, desde já, é que partindo do ponto em que se desprende da posição original, é que será possível chegar à justiça à luz do pensamento rawlsiano. Mas, para se ter uma solidariedade que é o foco deste trabalho, é preciso que sejam percorridos os 4 (quatro) estágios, pois somente assim é que será possível pensar em um ideal de justiça ambiental cooperativa, quando o indivíduo se desprende de uma visão egoística e atinge um interesse cooperativo. Mas, isso será melhor tratado no tópico subsequente.

\section{O PRINCÍPIO DA SOLIDARIEDADE AMBIENTAL}

Em primeiro lugar, consigna-se que o atual ordenamento jurídico brasileiro vem sofrendo ao longo dos anos, forte inspiração principiológica. Mais que isso, não somente inspiração, mas a devida incorporação à "letra da lei” de princípios que são vetores hermenêuticos interpretativos de grande relevância.

Com a relevância dos princípios no atual ordenamento jurídico, a Constituição acaba por remeter seus vetores para os diversos ramos e setores da sociedade. Nesse momento, o grande papel do intérprete é identificar o que já está disposto nos direitos garantidos constitucionalmente, ainda que de forma implícita (SARLET, 2007, p. 47).

É preciso ter visão de futuro, pois a grande crise global vivida nos tempos atuais é, sem dúvida, a ambiental (SANTOS, 2013, p. 300), com o enfrentamento de queimadas, incêndios, destruição de florestas e erosão do solo, aquecimento global, dificuldade de acesso a água potável, etc. Para enfrentar esse problema é preciso pautar na solidariedade transnacional e intergeracional.

Antes de adentrar ao princípio da solidariedade ambiental, é necessário pensar no pilar ideal de desenvolvimento sustentável ${ }^{4}$ a ser assegurado. Isso porque, o desenvolvimento sustentável é apresentado como o ideal de futuro, quando compete a qualquer pessoa

\footnotetext{
${ }^{4}$ Como o objetivo do artigo é falar sobre solidariedade ambiental, apresenta-se somente poucas concepções do princípio/direito do desenvolvimento sustentável.
} 
resguardar o meio ambiente ecologicamente equilibrado em conjunto com o desenvolvimento econômico e social (BARBIERI, 2020, p. 22).

O desenvolvimento sustentável, como conceito é uma teoria multidimensional, que encontra diversos objetivos a serem concretizados, dentre os principais estão os sociais e éticos (SACHS, 2008, p. 71) (solidariedade síncrona), mas também o pilar ambiental (solidariedade diacrônica com as gerações futuras), e o crescimento econômico. Esses três pilares precisam andar juntos e de mãos dadas ao crescimento, com a diminuição de desigualdades sociais existentes.

Importante destacar que o desenvolvimento sustentável é um alicerce da solidariedade, pois foi através da Revolução Ambiental que apresenta o fundamento da ética imperativa, também conhecido como solidariedade diacrônica (SACHS, 2009, p. 49) com as futuras gerações que se fala em possibilidade de pensar o meio ambiente para o futuro de toda a população e espécies de vida.

O dicionário da língua portuguesa traz a palavra solidariedade como "manifestação desse sentimento com o propósito de ajudar; ajuda, amparo, apoio" (HOUAISS, VILLAR, 2009, p. 453). Quando se afirma que a ideia de solidariedade é esse sentimento de ajuda e amparo, é preciso, portanto, compreender que ela pode ocorrer entre as nações e entre as gerações.

Por isso, ao se trabalhar com a ideia de solidariedade é necessário se remeter ao que o próprio comando constitucional determina de que há uma necessidade de proteger o meio ambiente para as presentes e futuras gerações. Isso porque, a busca de igualdade, equidade e solidariedade (SACHS, 2008, p. 14) é pautado nos termos das gerações de direitos humanos como objetivos macros a serem alcançados. E, além disso, esses pilares são parte do conceito de desenvolvimento sustentável para o futuro.

A ideia do pensar solidário é a de contribuir para que não ter em qualquer momento, soluções que tragam retrocesso ao que já foi conquistado ao longo de décadas. Tratando-se de direito de terceira dimensão (BONAVIDES, 2006, p. 115), é importante demonstrar que as conquistas que foram geradas, não poderão em hipótese alguma trazer um retrocesso (PRIEUR, 2012, p. 13). Para tanto, percebe-se que a Constituição deve ser lida de maneira extensiva/ampliativa, visto que os direitos e garantias fundamentais não merecem uma hermenêutica restritiva (FERREIRA, 2000, p. 58).

O que se pretende é garantir um mínimo de dignidade ao ser humano, para que 
possam ser assegurados recursos que atendam a sociedade atual e as gerações futuras. Além de um dever, o comando estabelece responsabilidades da atual geração, com as vindouras (SARLET, FENSTERSEIFER, 2014, p. 74). Ao se estabelecer a necessidade de proteger as presentes e futuras gerações, se faz presente a necessidade de que o discurso do legislador tenha que se pautar por todos os avanços em termos ambientais que a legislação já enfrentou.

A despeito das críticas que existam sobre essa deferência que a Constituição tenha para com o estabelecimento de responsabilidades com as gerações futuras, não há como se deixar de demonstrar que um dos focos da solidariedade é justamente esse. Afirmar-se que o problema da Constituição seria impedir que gerações futuras deliberassem sobre determinados assuntos de importância coletiva, deve ser sobrelevado, ao passo que esse mesmo diploma deve se preocupar com a promoção dos direitos humanos (SOUZA NETO, 2016, p. 28-29).

Tanto é assim, que a Corte Interamericana de Direitos Humanos, já respondeu na consulta n. ${ }^{\circ}$ 23/2017 (CORTE INTERAMERICANA DE DIREITOS HUMANOS), acerca da importância do meio ambiente, como direito humano, ante a impossibilidade de dissocia-lo desse conceito, uma vez que ocorre a interdependência e indivisibilidade entre os direitos humanos e a proteção do meio ambiente.

Dessa forma, a solidariedade intergeracional é a meta mais difícil de ser alcançada, pois "a gravidade do problema ambiental reside antes de mais no modo como afetará as próximas gerações, pelo que a sua resolução assenta forçosamente num princípio de responsabilidade intergeracional e numa temporalidade de médio e longo prazo" (SANTOS, 2013, p. 302). É complicado de se pensar a longo prazo, haja vista que as metas de governos, atualmente, têm se pautado quase que exclusivamente em medidas a curto prazo.

Ademais, com essas escolhas difíceis, no tempo e no espaço, é que será possível compreender quais as decisões mais acertadas a essa ou àquela situação, sempre pautado no desenvolvimento sustentável e no olhar distante de tempo. A defesa do meio ambiente, na concepção da solidariedade ambiental, faz com que se possa interpretar essa lógica acerca da garantia da dignidade humana, ou mesmo, de um mínimo existencial à vida digna.

Por outro lado, a solidariedade enquanto atuação mútua entre os diversos países do globo é aquela fundamentada na ideia de que o "mundo inteiro [é] integrante de uma mesma 'aldeia global' em termos ecológicos” (SARLET, FENSTERSEIFER, 2014, p. 73). Isso quer dizer que todas as pessoas do planeta estão juntas, pois o meio ambiente é ubíquo não fazendo

\footnotetext{
5 "la interdependencia e indivisibilidad entre los derechos humanos y la protección del médio ambiente".
} 
quaisquer diferenciações.

Ademais, o princípio n 7 da Declaração do Rio, deixa claro que "os Estados irão cooperar, em espírito de parceria global, para a conservação, proteção e restauração da saúde e da integridade do ecossistema terrestre" (ONU, 1992). Assim, a busca da solidariedade é pautada na fraternidade e na ajuda mútua entre os povos, na incessante busca de equilibrar as relações sociais, econômicas e ambientais existentes entre Norte e Sul (SANTOS, 2013, p. 302), bem como os devidos deveres e responsabilidades, no plano interno e internacional.

Tem-se evidente, portanto, que a dignidade possui suas variáveis incidentes sobre a proteção do meio ambiente. E como demonstrado aqui, há cumprimento do dever de que para dizer que algo está relacionado com dignidade da pessoa humana, é preciso que o intérprete fundamente a conexão direta ou indireta com o preceito, a fim de que não se tornem palavras vazias (SARMENTO, 2016, p. 310). Para isso, busca a concepção de justiça no olhar da Teoria da Justiça de Rawls para analisar o princípio da solidariedade ambiental e o problema da justiça entre gerações.

\section{PROBLEMA DA JUSTIÇA ENTRE GERAÇÕES CONJUGADA À SOLIDARIEDADE AMBIENTAL}

Após a compreensão do pensamento Rawlsiano, é preciso interpretar em que medida esse pensamento se aplica ao direito ambiental e como os fundamentos teóricos, sob o manto da Constituição de 1988, podem se inspirar nesse ideal de justiça. Isso porque, cabe ao intérprete olhar para os fatos jurídicos com olhar crítico, desvinculado de preconcepções.

Ao se partir da concepção de Rawls sobre o direito ambiental, é premente observar que o Legislativo é formado por pessoas dos mais diversos ramos da sociedade civil, desde empresários a trabalhadores do fim da escala de produção. Nesse sentido, cada um que ali está, possui uma vivência de mundo diferente do outro, pois “cada geração deve não apenas preservar os ganhos de cultura e civilização, e manter intactas aquelas instituições justas que foram estabelecidas" (RAWLS, 2002, p. 315). Classes sociais diferentes, culturas diferentes, concepções de mundo diferentes, convivem harmonicamente entre seus pares.

Ocorre que, a legitimidade da democracia representativa, confere a esses indivíduos o poder de criar as leis que tenham aptidão a defender os interesses da sociedade. Esses interesses, em nenhuma hipótese, podem ser contrários ao mínimo existencial já estabelecido 
pela Carta Constitucional vigente. Quando estão munidos de seu Poder de criar legislações, do debate, será possível chegar a algumas medidas que atendam a um maior número de pessoas de acordo com suas realidades.

O que se quer afirmar que, muito embora cada um dos representantes do povo que ali estão, tenham suas pretensões próprias de mundo, cabe ao legislativo refletir sobre as questões da nação e definir de forma a garantir o máximo de proteção de direitos à população. É aqui que vem a defesa que se faz com a teoria rawlsiana. Perceba-se que, os interesses individuais de cada um dos políticos, com o intuito de se permitir a existência de uma justiça ambiental, não podem se sobrelevar em detrimento do direito da coletividade. O equilíbrio é fundamental para se evitar o retrocesso de direitos ambientais.

Isso porque, é preciso saber se os sistemas social e econômico envolvem um número de instituições básicas, para só assim satisfazer os princípios da justiça, que com base somente na equidade ficaria incompleta (RAWLS, 2002, p. 314). Para conquistar o ideal de justiça dependeria, incialmente, de um mínimo social, uma vez que "a geração presente é obrigada a respeitar as reivindicações de seus sucessores" (RAWLS, 2002, p. 314). Para a conquista da essência do mínimo social é imprescindível que a riqueza média do país seja contemplada e haja igualdade de oportunidades entre as pessoas para o aumento da média.

Por esse motivo, o direito intergeracional ao meio ambiente possui total relação à teoria rawlsiana. Mas, a teoria não fundamenta apenas a lógica entre gerações. Para que a justiça ambiental se qualifique de maneira adequada, deve-se utilizar o véu da ignorância proposto por John Rawls, a fim de lhe possibilitar se destacar de seus laços fortes em sociedade. Ao que se depreender, do dissenso existente, é que se torna possível criar novos consensos capazes de evoluir a sociedade.

Por esse motivo, quando a pessoa está "despida" de sua posição original, tende ela a poder pensar de forma a gerar uma maior cooperação entre os envolvidos. A cooperação sob o viés intergeracional, trata-se da contribuição que os legisladores demonstram na atualidade, com o objetivo do crescimento da sociedade. E ainda, quando esse crescimento não se torna efetivo, é possível a utilização de outra estrutura do Judiciário, para solucionar o impasse.

Em uma visão macro, ao se analisar a cooperação entre os povos, depreende-se que a sistemática de justiça também possui seus reflexos. Porém, ao se associar à cooperação entre povos, o que se requer é uma visão global do meio ambiente. E essa visão global, desprovida de preconcepções. 
Por isso, o pensar contratualista pautado por Rawls entende que o problema da solidariedade intergeracional, pautado no primeiro pensar de justiça da posição original, deve ser fincada no princípio da poupança adequada (RAWLS, 2002, p. 317). Isso porque, a poupança deve ser trabalhada em conjunto com o princípio da diferença, pois ambos buscam que cada pessoa da atualidade contribua em favor das futuras gerações.

Aqui, o que se pretende é trazer uma concepção diversa daquela que já se encontra inserida na ideia de posição original, pois ela "é uma interpretação específica da situação inicial de escolha, situação em que os indivíduos se encontram para concluir o contrato: escolher os princípios da justiça adotados para governar sua sociedade" (LEMAIRE, 1997, p. 14).

A partir daí que se percebe a importância do véu da ignorância, que possui como agir nesse ponto específico. Tanto é que, quando se está a tratar de comunidade internacional, o foco não é pensar nos reflexos do meio ambiente para aquele Estado-nação de forma isolada, mas de pensar os reflexos a nível global. O que o véu da ignorância faz, é se utilizar de um artifício para anular "em posições de disputa, tentando-os a explorar as circunstâncias naturais e sociais em seu próprio benefício" (RAWLS, 2002, p. 91).

Dessa forma, o véu da ignorância se completa quando se interpreta a posição original a partir das trocas econômicas e sociais das gerações futuras e atuais, pautado no princípio da poupança, que "se aplica ao que a sociedade deve poupar por uma questão de justiça" (RAWLS, 2002, p. 318). Isso é ajustado no que as gerações presentes precisam saber e, assim, modificar as suposições iniciais de que é necessário realizar a poupança da natureza, precisando concordar com essa posição para que produza efeitos justos.

Importantes documentos internacionais, como os tratados internacionais, são assinados cotidianamente, com as preocupações de vários Chefes de Estado, com as consequências que podem advir de problemas climáticos no futuro. Dentre os acordos mais recentes com essa preocupação está o Acordo de Paris. O processo de desertificação em várias regiões do planeta, acrescido à quantidade de pessoas que passara a ser denominados de refugiados do clima (LOWE, 2014), demonstra que o ser humano tem adotado posturas equivocadas.

Daí o motivo de se pensar em estratégias para abranger o maior número de países possíveis, pois "todas as gerações estão virtualmente representadas na posição original, já que o mesmo princípio seria sempre escolhido" (RAWLS, 2002, p. 320). Não é possível mais 
imaginar que em nome do progresso e desenvolvimento econômico, as questões ambientais sejam deixadas de lado, é preciso que o princípio da poupança realizado.

No caso brasileiro, isso está mais que evidenciado. De uma simples leitura do art. 170, da Carta Constitucional de 1988, consta no inciso VI, entre os princípios da ordem econômica: "defesa do meio ambiente, inclusive mediante tratamento diferenciado conforme o impacto ambiental dos produtos e serviços e de seus processos de elaboração e prestação" (BRASIL, 1988).

Se para a ordem econômica a importância é a proteção do meio ambiente, é em razão dela que todos os vetores de interpretação devem partir. E, por esse motivo, quando se trata de estabelecer que o direito ambiental é o mais fulcral dos direitos, na medida em que lhe cabe estabelecer essa cooperação mútua, seja interna ou internacional, é a justiça de Rawls que nos fundamenta na regra cooperativa.

Ademais, para alcançar o ideal democrático de justiça é necessário ir além do primeiro passo da posição original, ultrapassar o véu da ignorância e chegar ao quarto estágio, que trata da aplicação concreta, pois "o princípio da poupança representa uma interpretação, formulada na posição original, do dever natural previamente aceito de defender e promover instituições justas" (RAWLS, 2002, p. 320).

Para tanto, há o caráter ético do curso da história, que demonstra a importância de o último estágio para a sociedade encontrar o verdadeiro sentido de justiça. Isso é, as gerações devem fazer parte e querer fazer parte da aplicação da solidariedade para que seja significativo e efetivo os seus objetivos. Por isso, "a vida de um povo é concebida como um sistema de cooperação que se estende ao longo do tempo histórico" (RAWLS, 2002, p. 322), o que fundamenta a concepção de justiça pautada no ideal das pessoas que vivem em seu determinado momento.

Portanto, o aumento da riqueza e percepção da atuação enquanto ser existente no mundo é importante para a conscientização da coletividade para o futuro, uma vez que as gerações sempre precisarão economizar e poupar para as gerações futuras não ficarem adstritas da natureza e de qualidade de vida e, somente assim, serão realizadas as instituições e as liberdades e igualdades.

\section{CONSIDERAÇÕES FINAIS}


A discussão em torno do Direito Ambiental é extremamente rica e importante para os momentos atuais. Tempos de grandes catástrofes ambientais, de egocentrismo político e visão estritamente economicista. Entender a forma como a doutrina e a legislação se porta diante desse preceito, nos leva a crer que se precisa, cada vez mais, de um debate intenso acerca da garantia desse direito tão importante a todos, afinal, a meta a ser alcançada é o crescimento pautado no desenvolvimento sustentável.

O Direito ambiental é muito mais que um direito individual, é um direito coletivo, no qual a preocupação deve se dar, em especial, tendo em vista os vários problemas que a sociedade tem enfrentado, dentre eles a poluição exagerada, efeito estufa e o aumento substancial da temperatura global. As consequências dessas atitudes, geram como consequência, fatores que interferem na vida de todo o planeta: seja para essa geração, seja para as futuras. Por esse motivo, a sociedade deve pensar no futuro e poupar o meio ambiente para que haja justiça.

Ao que tudo indica, a teoria de justiça em Rawls se encaixa perfeitamente na lógica envolvida com a solidariedade intergeracional. Isso quer dizer que, na medida em que se deve pensar em uma justiça pensada em prol da coletividade com equidade, a justiça ambiental acaba se firmando, quando se coloca em evidência os pilares de proteção ao meio ambiente, através do princípio da poupança.

Não é em outra medida, que a retirada da posição original, se mostra como uma das questões mais importantes na teoria de Rawls voltada à proteção do meio ambiente. Isso porque, é a partir dela, que se mostra clara a preocupação com o que de fato seja importante na defesa. Não se pode esquecer da aplicação dos fatos ao caso concreto, haja vista que as condutas protetivas do meio ambiente devem ser realizadas por qualquer país e por qualquer pessoa, pois é ubíquo e tem que ser pensado para as futuras gerações.

Quando o autor delimita a necessidade de distribuição e deveres e responsabilidades às pessoas, ele nada mais faz que determinar à sociedade sua parcela de culpa por todos os problemas que podem ser gerados nos mais variados setores. Com isso, torna-se possível perceber e prever em que medida a justiça irá atuar em relação ao tema. E, nesse caso, a justiça ambiental.

Importa, nesse sentido, a preocupação com o que a solidariedade ambiental tem a oferecer a teoria de justiça estudada. O que se conclui é que quaisquer tentativas de modificação daquilo que já está definido e mais protetivo, é atacar frontalmente preceitos que 
já foram deliberados em momento anterior, na tentativa de atingir o foco de manutenção da dignidade da coletividade.

Por isso, muito mais que garantir a solidariedade entre gerações, é preciso observar a solidariedade entre os povos, pois é a partir dela que o planeta conseguirá se sustentar pelos próprios milênios. Já não há mais como pensar que o ser humano é um ser isolado e independente das intempéries geradas no meio ambiente: pelo contrário.

Consequências trazidas de um continente ao outro, podem trazer consequências graves aos cidadãos daquele país. Para solucionar isso é preciso agir de forma cooperativa, pois um país na comunidade global só estará devidamente integrado, caso ele tenha parceiros aptos a contribuir para o sucesso do intento.

A partir daí é que se percebe que a justiça distributiva em Rawls traz essa visão panorâmica de que, para que o meio ambiente seja, de fato, um importante instrumento para a proteção da vida e da dignidade de todos, é necessário que ao serem criados os instrumentos cooperativos, se determine uma visão de cooperação e, nunca, individualista ou segregacionista.

A justiça ambiental, de fato, somente será possível, na medida em que internalizar o véu da ignorância, ao ponto de pensar, exatamente, como as políticas ambientais poderão auxiliar no crescimento das presentes e futuras gerações, com essa visão de que há uma necessidade colaborativa de todos.

\section{REFERÊNCIAS BIBLIOGRÁFICAS}

BARBIERI, José Carlos. Desenvolvimento sustentável: das origens à Agenda 2030. Petrópolis: Vozes, 2020.

BELCHIOR, Germana Parente Neiva. Hermenêutica jurídica ambiental. São Paulo: Saraiva, 2011.

BONAVIDES, Paulo. Curso de direito constitucional. 18. ed. São Paulo: Malheiros, 2006.

BRASIL. Constituição [da] República Federativa do Brasil. Brasília: Congresso Nacional, 1988. Disponível em: <http://www.planalto.gov.br/ccivil_03/constituicao/constituicao.htm>. Acesso em: 22. jan. 2021.

CORTE INTERAMERICANA DE DIREITOS HUMANOS. Opinião Consultiva n. 23/2017 ("Meio Ambiente e Direitos Humanos"), p. 25. Disponível em: <http://www.corteidh.or.cr/ docs/opiniones/seriea_23_esp.pdf>. Acesso em 16. Jan. 2021. 
FARO, Julio Pinheiro. Um conceito de dignidade da pessoa humana (I): um ponto de partida a teoria da Justiça como equidade revisitada. In: Revista do Instituto do Direito Brasileiro, Ano 1 (2012), no 4, p. 1991-2040.

FERRAZ JÚNIOR, Tercio Sampaio. Introdução ao estudo do Direito: técnica, decisão, dominação. 4. ed. São Paulo: Atlas, 2003.

FERREIRA, Manoel Gonçalves Filho. Direitos Humanos Fundamentais. 4. ed. São Paulo: Saraiva, 2000.

FURLAN, Fabiano Ferreira. O debate entre John Rawls e Jürgen Habermas sobre a concepção de justiça. Belo Horizonte: Arraes Editores, 2012.

HOUAISS, Antônio; VILLAR, Mauro de Salles. Dicionário Houaiss da língua portuguesa. 1. ed. Rio de Janeiro: Objetiva, 2009.

KELSEN, Hans. Teoria Pura do Direito. 8. ed. São Paulo: Martins Fontes, 2011.

LEMAIRE, André. L'enjeu de la rationalité dans la théorie de la justice de John Rawls. 1997. Dissertação (Mestrado em Filosofia) - Universidade de Sherbrooke, Faculdade de Teologia, de Ética e de Filosofia. p.14 (tradução livre)

LOWE, Daniel. Refugiados climáticos: ¿quién debe cargar los costos?. Revista Interdisciplinar de Mobilidade Humana, v. 22. n. 43, Brasilia, jul/ dez. 2014. Disponível em: $<$ https://www.scielo.br/scielo.php?pid=S1980-85852014000200011\& script=sciartt ext\&tlng=es>. Acesso em: 16. jan. 2021.

MÖLLER, Josué Emílio. A justiça como equidade em John Rawls. Porto Alegre: Sergio Antonio Fabris Editor, 2006.

NEDEL, José. A teoria ético-política de John Rawls: uma tentativa de integração de liberdade e igualdade. Porto Alegre: EDIPUCRS, 2000. 200 p.

NUNES JÚNIOR, Amandino Teixeira. A teoria rawlsiana da Justiça. Revista de Informação Legislativa, v. 42, n. ${ }^{\circ} 168$, p 215-225, out./dez. 2005

POGGE, Thomas. John Rawls: his life and theory of justice. EUA: Oxford University Press. 2007 (tradução livre)

PRIEUR, Michel. O princípio da proibição de retrocesso ambiental. In: SENADO FEDERAL. O princípio da proibição de retrocesso social. Brasília: Senado Federal, 2012.

RAWLS, John. Justice as Fairness: A Restatement. Edited by Erin Kelly. Cambridge: Harvard University Press, 2001.

RAWLS, John. Uma teoria da justiça. Trad. Almiro Pisetta e Lenita Maria Rímoli Esteves. 2. ed. São Paulo: Martins Fontes, 2002. 
SACHS, Ignacy. Caminhos para o desenvolvimento sustentável. Rio de Janeiro: Garamond, 2009.

SACHS, Ignacy. Desenvolvimento: includente, sustentável, sustentado. Rio de Janeiro: Garamond, 2008.

SANTOS, Boaventura de Sousa. Pela mão de Alice: o social e o político na pós-modernidade 14. ed. São Paulo: Cortez, 2013.

SARLET, Ingo Wolfgang. A Eficácia dos Direitos Fundamentais. 7.ed., Porto Alegre: Livraria do Advogado, 2007.

SARLET, Ingo Wolfgang; FENSTERSEIFER, Tiago. Princípios do direito ambiental. São Paulo: Saraiva, 2014.

SARMENTO, Daniel. Dignidade da pessoa humana: conteúdo, trajetórias e metodologia. 2. ed. Belo Horizonte: Fórum, 2016.

SEM AUTOR: Para Macron, Amazônia é 'bem comum' e pede 'mobilização de potências' contra desmatamento. Jornal G1. Sem cidade, 24. Ago. 2019. Seção Mundo. Disponível em: <https://g1.globo.com/mundo/noticia/2019/08/24/para-macron-amazonia-ebem-comum-e-pede-mobilizacao-de-potencias-contra-desmatamento.ghtml $>$. Acesso em: 22. Jan. 2021.

SILVA, Ricardo Perlingeiro Mendes da. Teoria da Justiça de John Rawls. Revista de Informação Legislativa, Brasília, v. 35, n. 138, p. 193-212, abr./jun. 1998.

SOUZA NETO, Claudio Pereira de; SARMENTO, Daniel. Direito constitucional: teoria, história e métodos de trabalho. 2. ed. Belo Horizonte: Fórum, 2016.

TREDANARO, Emanuele. A abordagem contratualista de "A theory of Justice" entre método e objetivos. Algumas observações a partir das últimas críticas de Onora O’Neill. In:

KRITERION, Belo Horizonte, nº 136, Abr./2017, p. 65-86. 